\title{
Evaluasi Usability Website dengan Website Usability Evaluation tool dan Importance-Performance Analysis
}

Website Usability Evaluation using Website Usability Evaluation tool and ImportancePerformance Analysis

\author{
Hovely Wahyu Zaputra Simatupang ${ }^{1}$, Sri Widowati ${ }^{2}$, Rosa Reska Riskiana ${ }^{3}$, Aqila Fitri Alitu ${ }^{4}$ \\ 1,2,3,4Fakultas Informatika, Universitas Telkom \\ E-mail: ${ }^{1}$ hovelywahyu@ @student.telkomuniversity.ac.id, ${ }^{2}$ sriwidowati@telkomuniversity.ac.id, \\ ${ }^{3}$ rosareskaa@ telkomuniversity.ac.id, ${ }^{4}$ aqilahfitri@ student.telkomuniversity.ac.id
}

\begin{abstract}
Abstrak
Pariwisata merupakan program unggulan pemerintah khususnya pemerintah daerah. Dalam menyebarkan informasi dan meningkatkan pelayanan publik pada bidang pariwisata, Dinas Kebudayaan dan Pariwisata Kota Bandung telah menerapkan sistem informasi e-government berbasis website. Namun, terdapat berbagai keluhan dari pengguna website Dinas Kebudayaan dan Pariwisata Kota Bandung yang menyebutkan bahwa informasi pada website sulit ditemukan, respon website cukup lama, dan lain sebagainya. Maka dari itu, perlu dilakukan evaluasi usability pada website tersebut untuk meningkatkan kemudahan dan efisiensi saat digunakan. Untuk mengevaluasi usability website digunakan metode pengukuran dari sudut pandang pengguna, yaitu Website Usability Evaluation Tool (WEBUSE). Hasil evaluasi WEBUSE diukur menggunakan metode Importance-Performance Analysis (IPA) untuk mengetahui perbaikan-perbaikan yang perlu diprioritaskan. Hasil pengukuran menunjukkan usability website saat ini berada pada level Moderate dengan nilai 0,56, sedangkan website perbaikan berada pada level Good denga nilai 0.78. Hasil performance (kinerja) website saat ini memiliki nilai rata-rata 3,25 , sedangkan performance website perbaikan memiliki nilai rata-rata 4,10. Sebelas permasalahan website saat ini yang masuk ke dalam kuadran concentrate here meningkat pada website perbaikan menjadi kuadran keep up the good work.
\end{abstract}

Kata kunci: Evaluasi, Importance-Performance Analysis, Usability

\begin{abstract}
Tourism is the government's flagship program, especially local government. In disseminating information and improving public services in the tourism sector, the Bandung City Culture and Tourism Office has implemented a website-based e-government information system. However, there were various complaints from users of the Bandung City Culture and Tourism Office website which stated that the information on the website was difficult to find, the website response was quite long, and so on Therefore, it is necessary to evaluate the usability of the website to increase the ease and efficiency when used. To evaluate the usability of the website, a measurement method from the user's point of view is used, namely the Website Usability Evaluation Tool (WEBUSE). The results of the WEBUSE evaluation are measured using the Importance-Performance Analysis (IPA) method to determine the improvements that need to be prioritized. The measurement results show that the website usability is currently at the Moderate level with a value of 0.56, while the improvement website is at the Good level with a value of 0.78. The results of website performance currently have an average value of 3.25 , while improved website performance has an average value of 4.10. Eleven current website problems that are included in the concentrate here quadrant increased on the improvement website to the keep up the good work quadrant.
\end{abstract}

Keywords: Evaluation, Importance-Performance Analysis, Usability 


\section{PENDAHULUAN}

Dinas Kebudayaan dan Pariwisata Kota Bandung telah menerapkan teknologi informasi dan komunikasi berbasis website (situs web) guna mencapai tujuan dan sasaran pemerintah Kota Bandung, yaitu menyebarluaskan informasi, memberikan pelayanan publik, dan meningkatkan perekonomian masyarakat Kota Bandung pada sektor kebudayaan dan pariwisata. Namun, berdasarkan wawancara yang dilakukan kepada pengguna website Dinas Kebudayaan dan Pariwisata Kota Bandung didapatkan adanya beberapa permasalahan, antara lain pengguna kesulitan dalam menemukan informasi, fitur-fitur yang dibutuhkan tidak ditemukan pada website, tampilan website yang kurang responsif pada beberapa fungsi, dan respon website cukup lama. Hal ini menyebabkan ketidakpuasan pengguna dalam menggunakan situs web tersebut [1]. Selain itu, Kepala Divisi Data dan Informasi Dinas Kebudayaan dan Pariwisata Kota Bandung menyebutkan bahwa website Dinas Kebudayaan dan Pariwisata Kota Bandung belum pernah dievaluasi.

Pada umumnya, keberhasilan pengembangan sebuah website dapat diukur berdasarkan aspek usability. Usability mengarah kepada bagaimana pengguna bisa mempelajari dan menggunakan sebuah website untuk mencapai tujuannya dan seberapa puas mereka terhadap penggunaannya[1]. Tingkat usability menunjukkan seberapa besar sebuah website dapat diterima oleh pengguna dan digunakan dalam jangka waktu yang panjang[2]. Oleh karena itu, dibutuhkan metode yang tepat untuk mengevaluasi usability sebuah website.

Pada penelitian [3][4][5] metode WebQual digunakan untuk mengevaluasi kualitas usability, kualitas informasi, dan kualitas interaksi berdasarkan pandangan pengguna terhadap situs web yang akan dievaluasi. Ketiga penelitian tersebut menggabungkan metode evaluasi website WebQual dengan metode Importance-Performance Analysis (IPA) untuk menentukan prioritas perbaikan website. Adapun penelitian [6][7] juga melakukan evaluasi terhadap situs web dengan fokus hanya ke aspek usability menggunakan metode Website Usability Evaluation tool (WEBUSE). Dari perbandingan beberapa penelitian tersebut, metode yang dipilih untuk mengevaluasi website Dinas Kebudayaan dan Pariwisata Kota Bandung adalah metode WEBSUE, karena fokus masalah yang ingin diatasi adalah aspek usability dari website tersebut. WEBUSE juga sudah mencakup seluruh aspek usability dari berbagai metode usability tool, yaitu WAMMI, webSAT, Bobby, dan protocol analysis[8].

Metode WEBUSE merupakan metode untuk mengetahui permasalahan usability yang baik dan buruk pada berbagai jenis website [9]. Metode WEBUSE terdiri dari 24 pertanyaan yang terbagi dalam 4 kategori, yaitu Content Organization and Readability, Navigation and Links, User Interface Design, dan Performance and Effectiveness [8]. Dari hasil evaluasi WEBUSE tersebut, akan dicari permasalahan yang diprioritaskan untuk diperbaiki dan dipertahankan menggunakan metode Importance-Performance Analysis (IPA)[3]. Metode ini digunakan karena mudah dipahami dan membutuhkan biaya yang rendah [10]. Selain itu, metode ini juga sudah dipakai pada beberapa penelitian untuk menentukan prioritas perbaikan. Namun, berbeda dengan penelitian-penelitian [3]-[7] yang tidak melakukan perbaikan terhadap website setelah dilakukan evaluasi, penelitian ini akan menggunakan hasil analisis dari evaluasi WEBUSE dan IPA sebagai acuan perbaikan website menggunakan buku panduan ResearchBased Web Design \& Usability Guidelines[11]. Hasil rekomendasi perbaikan akan diimplementasikan ke dalam bentuk prototype website yang akan dievaluasi kembali dengan metode yang sama dan dilakukan perbandingan terhadap hasil evaluasi website saat ini untuk mengetahui peningkatan yang didapatkan dari hasil evaluasi sebelumnya.

\section{METODE PENELITIAN}

Dalam penelitian ini metode evaluasi yang digunakan adalah metode Website Usability Evaluation tool (WEBUSE) dan metode Importance-Performance Analysis (IPA) untuk menganalisis hasil evaluasi WEBUSE. Tahapan penelitian yang dilakukan dapat dilihat pada gambar 1 berikut : 


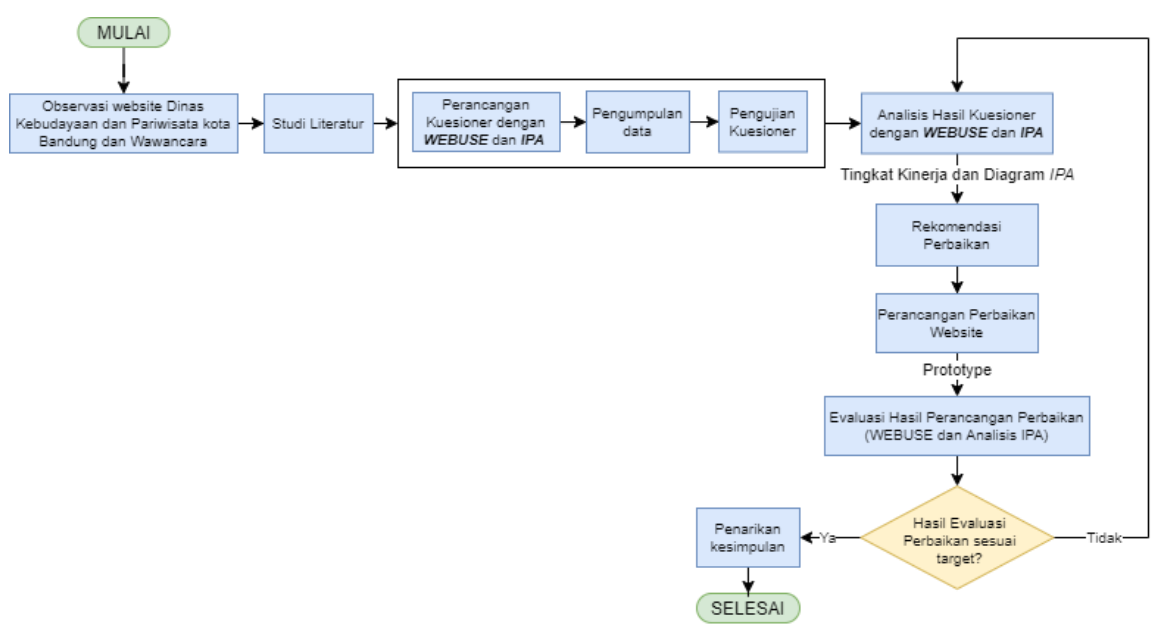

Gambar 1 Tahapan Penelitian

\subsection{Observasi, Wawancara, dan Studi Literatur}

Tahap awal penelitian ini adalah observasi dan wawancara. Tahap ini bertujuan untuk mempelajari kesesuaian menu, fungsi, konten informasi yang disediakan terhadap pengguna website. Berdasarkan hasil wawancara yang dilakukan terhadap pengguna website dan Kepala Divisi Data dan Informasi Dinas Kebudayaan dan Pariwisata Kota Bandung website saat ini masih memiliki banyak kekurangan, seperti kesulitan dalam menemukan informasi, tampilan yang tidak responsif, informasi yang dimuat tidak tertata dengan rapi, serta belum pernah dilakukan evaluasi.

\subsection{Studi Literatur}

Pada tahap ini dilakukan kajian terhadap berbagai literatur yang berkaitan dengan topik penelitian. Referensi yang digunakan sebagai acuan penelitian berasal dari jurnal, buku, atau conference paper yang berkaitan dengan pengukuran usability dan buku panduan untuk melakukan proses perbaikan website.

\subsection{Perancangan Kuesioner, Pengumpulan Data, dan Pengujian Kuesioner}

Pada tahap ini dilakukan perancangan kuesioner yang mengacu pada metode WEBUSE. Kuesioner dirancang berdasarkan metode analisis yang akan digunakan, yaitu Importance dan Performance. Dua metode tersebut digunakan untuk mengetahui faktor-faktor yang memengaruhi kepuasan pengguna dan faktor-faktor yang perlu ditingkatkan menurut pengguna. Pengumpulan data dilakukan berdasarkan perancangan kuesioner yang telah dilakukan pada tahap sebelumnya. Penentuan jumlah responden mengacu pada studi literatur yang telah dilakukan, yaitu bila sampel dibagi dalam beberapa kategori maka ukuran sampel yang layak dalam penelitian adalah minimal 30 orang. Pertanyaan pada kuesioner WEBUSE terdiri dari 24 pertanyaan dengan 5 opsi jawaban yang terbagi dalam empat dimensi, yaitu Content, organization and readability, Navigation and link, Design user interface, dan Performance and effectiveness[7]. Pertanyaan tersebut memiliki bobot masing-masing antara 1 sampai 5 dan akan dikonversi ke nilai merit seperti yang dijelaskan pada Tabel 1.

Tabel 1 Tabel bobot nilai merit[12]

\begin{tabular}{|l|c|}
\hline \multicolumn{1}{|c|}{ Pilihan } & Merit \\
\hline Sangat Tidak Setuju (STS) & 0.00 \\
\hline Tidak Setuju (TS) & 0.25 \\
\hline Netral (N) & 0.50 \\
\hline Setuju (S) & 0.75 \\
\hline Sangat Setuju (SS) & 1.00 \\
\hline
\end{tabular}

Hasil evaluasi WEBUSE berupa poin usability berdasarkan respon setiap pertanyaan yang diberikan kepada pengguna. Penilaian usability berdasarkan WEBUSE terdiri dari 
beberapa level yang dapat dilihat dari perhitungan poin usability. Tabel 2 di bawah menunjukan hubungan poin usability dengan level usability.

Tabel 2 Poin dan Level Usability Website (WEBUSE)
\begin{tabular}{|l|l|}
\hline \multicolumn{1}{|c|}{ Poin } & \multicolumn{1}{c|}{ Level Usability } \\
\hline $0 \leq x \leq 0.2$ & Bad \\
\hline $0.2 \leq x \leq 0.4$ & Poor \\
\hline $0.4 \leq x \leq 0.6$ & Moderate \\
\hline $0.6 \leq x \leq 0.8$ & Good \\
\hline $0.8 \leq x \leq 1.0$ & Excellent \\
\hline
\end{tabular}

Rata-rata setiap indikator pengukuran kepentingan (importance) dan kinerja (performance) dihitung menggunakan menggunakan rumus sebagai berikut:

$$
\begin{aligned}
& \text { Keterangan: } \\
& \bar{x}=\text { rata-rata hitung } \\
& x \mathrm{i}=\text { nilai sampel ke- } i \\
& n=\text { jumlah sampel }
\end{aligned}
$$$$
\bar{x}=\frac{1}{n} \sum_{1=1}^{n} x i(1)
$$

Penyebaran kuesioner dilakukan secara daring menggunakan Google Form. Kuesioner yang telah dikumpulkan akan diuji validitas dan reliabilitasnya. Kuesioner dinyatakan valid jika $\mathrm{R}$ hitung $>\mathrm{R}$ tabel dan reliabel jika angka Cronbach`s Alpha $(\alpha)$ kuesioner $>$ nilai minimal Cronbach's Alpha $(\alpha)$, yaitu 0,70. Jika kuesioner dinyatakan valid dan reliabel maka akan dilakukan analisis terhadap data kuesioner dengan metode IPA untuk memetakan permasalahan yang diperoleh, sehingga dapat diketahui perbaikan yang harus dilakukan untuk meningkatkan kualitas situs web dan kepuasan pengguna.

Hasil penelitian dengan menggunakan metode IPA disampaikan dengan menggunakan kuadran 2 dimensi yang memiliki empat kategori yang sering disebut dengan diagram kartesius. Nilai pada $\mathrm{x}$ merupakan nilai rata- rata dari tingkat kinerja setiap atribut, sedangkan nilai pada y merupakan nilai rata- rata dari tingkat kepentingan setiap atribut[13]. Empat kuadran dalam diagram kartesius tersebut dapat dilihat pada Gambar 2 berikut:

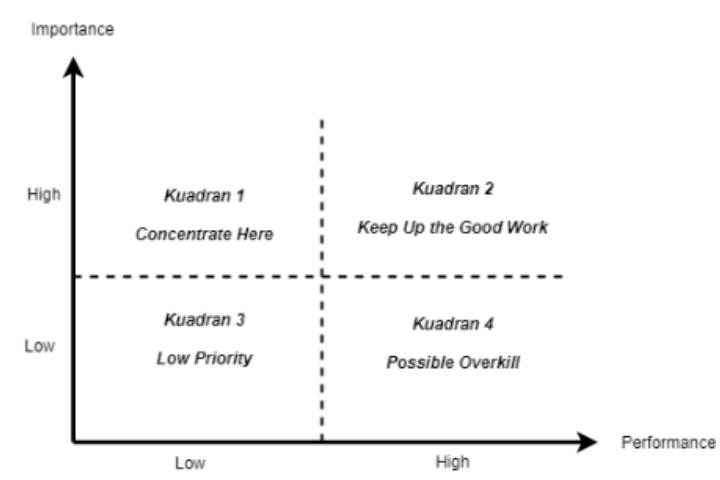

Gambar 2 Diagram Importance-Performance Analysis (IPA) [13]

1. Kuadran I: Concentrate Here (High Importance dan Low Performance). Kuadran ini harus diprioritaskan karena pengguna merasa layanan ini penting namun belum memberikan kepuasan karena tingkat kinerja rendah.

2. Kuadran II: Keep Up the Good Work (High Importance dan High Performance). Kuadran ini diharapkan tetap dipertahankan karena tingkat kepentingan dan kinerja tinggi. 
3. Kuadran III: Low Priority (Low Importance dan Low Performance). Tingkat kepentingan dan kinerjanya rendah. Pengguna tidak terlalu mementingkan layanan ini sehingga tidak perlu terlalu diperhatikan.

4. Kuadran IV: Possible Overkill (Low Importance dan High Performance). Pengguna tidak terlalu mementingkan layanan ini, namun kinerjanya tinggi. Sumber daya diharapkan dapat membantu faktor lain yang membutuhkan peningkatan kinerja.

\subsection{Analisis Hasil Kuesioner dan Rekomendasi Perbaikan}

Setelah menguji validitas dan reliabilitas, tahap selanjutnya adalah melakukan analisis kuesioner dengan menggunakan WEBUSE dan IPA untuk mengetahui tingkat kinerja dari website saat ini dan rata-rata setiap atribut pengukuran. Hasil pengukuran tersebut digunakan untuk mendapatkan usability point yang merepresentasikan level usability website seperti yang terdapat pada Tabel 2. Kemudian dilakukan pemetaan atribut pengukuran pada diagram IPA menggunakan nilai rata-rata Importance dan rata-rata Performance keseluruhan hasil kuesioner. Berdasarkan pemetaan tersebut diperoleh atribut pengukuran yang dijadikan sebagai acuan perbaikan dan atribut lainnya yang dapat diabaikan maupun dipertahankan.

Berdasarkan permasalahan yang ditemukan dari hasil evaluasi website saat ini, ditentukan rekomendasi perbaikan yang mengacu pada buku panduan pengembangan website yang berjudul Research-Based Web Design \& Usability Guidelines agar perbaikan yang dilakukan sesuai dengan permasalahan yang ditemukan. Rekomendasi perbaikan tersebut digunakan sebagai acuan dalam proses perancangan perbaikan yang dilakukan.

\subsection{Perancangan Perbaikan dan Evaluasi Prototipe}

Perancangan Perbaikan website mengacu pada permasalahan yang menjadi prioritas berdasarkan hasil analisis sebelumnya. Perancangan perbaikan menghasilkan prototipe rekomendasi yang akan diberikan kepada Dinas Kebudayaan dan Pariwisata Kota Bandung untuk meningkatkan efisiensi dan kepuasan pengguna website. Setelah prototipe selesai, prototipe tersebut akan dievaluasi kembali menggunakan kuesioner dengan responden yang sama dengan sebelumnya. Kemudian dilakukan pemetaan kembali menggunakan ImportancePerformance Analysis (IPA) terhadap hasil kuesioner website perbaikan tersebut untuk mengetahui kepuasan pengguna terkait perbaikan yang dilakukan dan pemetaan atribut pengukuran website hasil perbaikan pada diagram IPA.

\section{HASIL DAN PEMBAHASAN}

\subsection{Hasil Evaluasi Website Saat Ini}

Dari hasil kuesioner, website saat ini mendapatkan nilai rata-rata Importance sebesar 3, 90 degan nilai Performance sebesar 3,25. Nilai tersebut menunjukkan bahwa harapan pengguna terhadap kinerja dari website Dinas Kebudayaan dan Pariwisata Kota Bandung saat ini belum terpenuhi. Nilai usability point website saat ini yaitu 0,56 sehingga dapat diketahui usability website saat ini berada pada level usability Moderate. Berdasarkan nilai Importance dan Performance yang diperoleh, dilakukan perhitungan kesenjangan (gap) untuk mengetahui kepuasan pengguna dengan menghitung selisih nilai Performance dengan nilai Importance. Nilai kesenjangan (gap) pada website saat ini bernilai $-0,65$, artinya pengguna belum puas dengan kinerja website saat ini.

\subsection{Pemetaan Importance-Performance Kuesioner}

Hasil analisis menggunakan Importance-Performance Analysis (IPA) diinterpretasikan dalam diagram kartesius yang terbagi menjadi empat kuadran. Sumbu $\mathrm{X}$ adalah Performance dan sumbu Y adalah Importance. 


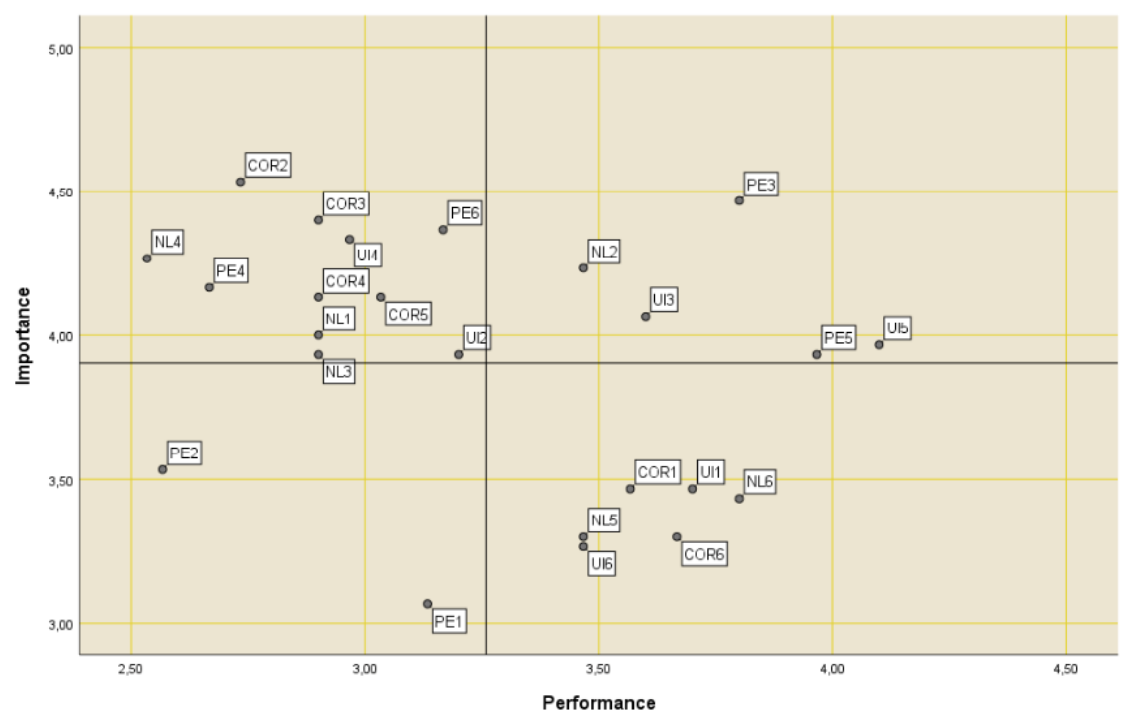

Gambar 3 Pemetaan indikator pengukuran website saat ini pada diagram IPA

Dari gambar pemetaan diatas, terdapat 11 (sebelas) atribut yang masuk dalam kuadran I sehingga menjadi prioritas perbaikan, yaitu COR2, COR3, COR4, COR5, NL1, NL3, NL4, UI2, UI4, PE4 dan PE6. Bagi pengguna, atribut tersebut sangat penting tetapi memiliki kinerja yang rendah. Pada kuadran II terdapat lima atribut yang harus dipertahankan yaitu NL2, UI3, UI5, PE3 dan PE5 karena kepentingan (importance) dan kinerja (peformance) yang tinggi. Pada kuadran III terdapat dua atribut yaitu PE1 dan PE2 yang tingkat kepentingan (importance) dan kinerja (peformance) rendah sehingga tidak perlu diperhatikan. Adapun atribut COR1, COR6, NL5, NL6, UI1 dan UI6 masuk pada kuadran IV yang artinya pengguna tidak terlalu mementingkan layanan tersebut, tetapi memiliki kinerja yang tinggi.

\subsection{Rekomendasi Perbaikan Website}

Berdasarkan hasil evaluasi website saat ini dan pemetaan setiap atribut, ditentukan rekomendasi perbaikan website yang mengacu pada pedoman Research-Based Web Design \& Usability Guidelines. Berikut rekomendasi perbaikan website yang dilakukan untuk meningkatkan level usability website.

Tabel 3 Daftar rekomendasi perbaikan website berdasarkan guidelines

\begin{tabular}{|l|l|l|}
\hline \multicolumn{1}{|c|}{ Kode } & \multicolumn{1}{|c|}{ Pernyataan } & \multicolumn{1}{c|}{ Guidelines } \\
\hline COR2 & Saya dapat dengan mudah menemukan & 9.5 Highlight Critical Data \\
& apa yang saya inginkan di dalam website & 9.6 Use Descriptive Row and Column Headings \\
& ini. & 12.2 Place Important Items at Top of the List \\
& & 16.1 Organize Information Clearly 17.6 Allow Simple \\
& & Searches \\
\hline COR3 & Isi/konten yang terdapat dalam website & $13: 6$ Minimize User Data Entry \\
& tertata dengan baik. & $16: 1$ Organization information clearly 16:4 Group Related \\
& & Elements \\
\hline COR4 & Saya dapat dengan mudah membaca & $9: 4$ Use unique and descriptive heading \\
& isi/konten website ini. & $9: 5$ Highlight critical data \\
& & $15: 7$ Limit the Number of Words and Sentences \\
& & $16: 1$ Organization information clearly \\
\hline COR5 & Saya nyaman dan terbiasa dengan bahasa & $15: 2$ Avoid Jargon \\
& yang digunakan pada website ini. & $15: 3$ Use Familiar Words \\
\hline NL1 & Saya dapat dengan mudah mengetahui & $7: 4$ Provide Feedback on Users' Location \\
& posisi keberadaan ketika menjelajahi & $7: 12$ Breadcrumb Navigation 10:1 Use meaningful link labels \\
& website ini atau dalam halaman apa saya & \\
& berada. & \\
& Saya dapat dengan mudah menjelajahi & $7: 3$ Use clickable 'list of contents' on long pages \\
& website menggunakan link yang ada atau & $7: 10$ Use Site Maps \\
& kembali ke halaman sebelumnya dengan & $10: 8$ Provide consistent clickability cues \\
& tombol kembali (back) pada browser. & \\
\hline
\end{tabular}




\begin{tabular}{|c|c|c|}
\hline NL4 & $\begin{array}{l}\text { Link dalam website ini berfungsi dengan } \\
\text { baik }\end{array}$ & $\begin{array}{l}\text { 10:2 Link to Related Content } \\
\text { 10:3 Match the link names with their destination pages }\end{array}$ \\
\hline UI2 & $\begin{array}{l}\text { Saya merasa nyaman dengan warna yang } \\
\text { digunakan dalam website ini. }\end{array}$ & $\begin{array}{l}\text { 11:1 use black text on plain, high-contrast backgrounds } \\
\text { 11:9 Color-Coding and Instructions 11:11 Highlighting } \\
\text { Information 12:3 Format Lists to Ease Scanning }\end{array}$ \\
\hline UI4 & $\begin{array}{l}\text { Website ini mempunyai tampilan yang } \\
\text { konsisten disemua halaman. }\end{array}$ & $\begin{array}{l}\text { 6:8 Use Fluid Layouts } \\
\text { 11:2 Format Common Items Consistently } \\
\text { 11:4 Ensure Visual Consistency 11:5 Use Bold Text Sparingly }\end{array}$ \\
\hline PE4 & $\begin{array}{l}\text { Website memberi respon/balasan yang } \\
\text { sesuai dengan harapan untuk setiap } \\
\text { tindakan yang saya lakukan. }\end{array}$ & $\begin{array}{l}\text { 2:10 Provide Feedback when Users Must Wait } \\
\text { 10:1 Use Meaningful Link Labels 10:2 Link to Related } \\
\text { Content } \\
\text { 10:3 Match Link Names with Their Destination Pages } \\
\text { 12:1 Order Elements to Maximize User Performance } \\
\text { 13:11 Anticipate Typical User Errors }\end{array}$ \\
\hline PE6 & $\begin{array}{l}\text { Website ini selalu memberikan pesan yang } \\
\text { jelas dan berguna ketika saya tidak tahu } \\
\text { bagaimana untuk memproses suatu hal } \\
\text { (aksi). }\end{array}$ & $\begin{array}{l}\text { 13:1 Distinguish Required and Optional Data Entry Fields } \\
\text { 16:7 Display Only Necessary Information }\end{array}$ \\
\hline
\end{tabular}

Tabel 3 merupakan rekomendasi terhadap atribut pengukuran yang masuk dalam kuadran I berdasarkan hasil analisis Importance-Peformance. Rekomendasi ditentukan berdasarkan pedoman agar perbaikan yang dilakukan relevan dengan permasalahan yang ditemukan dan untuk menghindari unsur subjektivitas peneliti dalam perancangan.

\subsection{Rancangan Perbaikan Website}

Berdasarkan rekomendasi perbaikan sebelumnya, dilakukan perubahan tata letak dan tampilan pada website Dinas Kebudayaan dan Pariwisata Kota Bandung. Prototipe dapat diakses pada link (www.hovsmtpng.com/disbudpar). Beberapa hasil perancangan perbaikan website dapat dilihat pada gambar berikut :

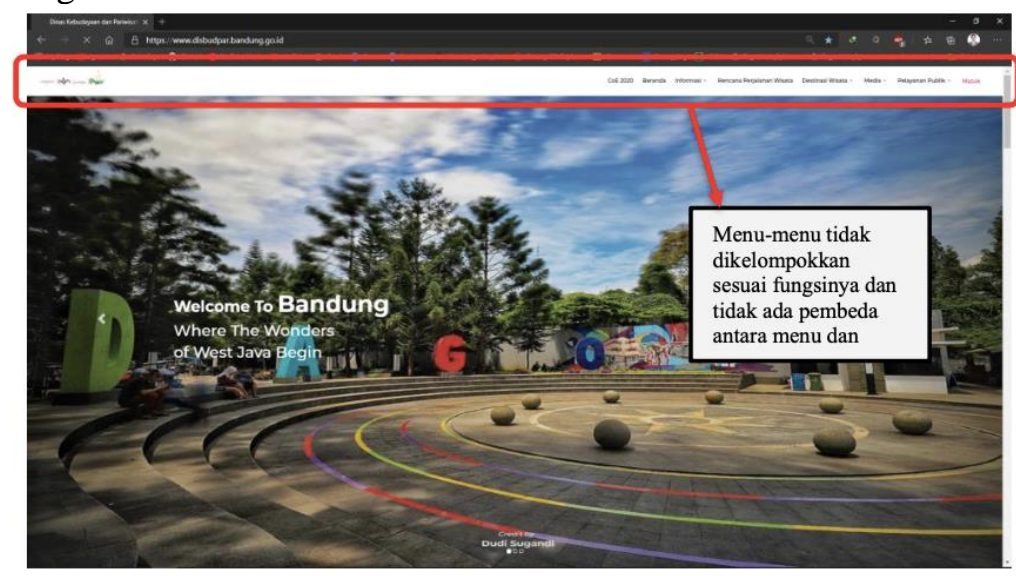

Gambar 4 Tampilan awal website saat ini

Gambar 4 merupakan tampilan awal website saat ini. Dapat dilihat bahwa menu pada header tidak tertata dengan baik sehingga perlu dilakukan pengelompokan informasi sesuai panduan 16:1 Organization information clearly. 


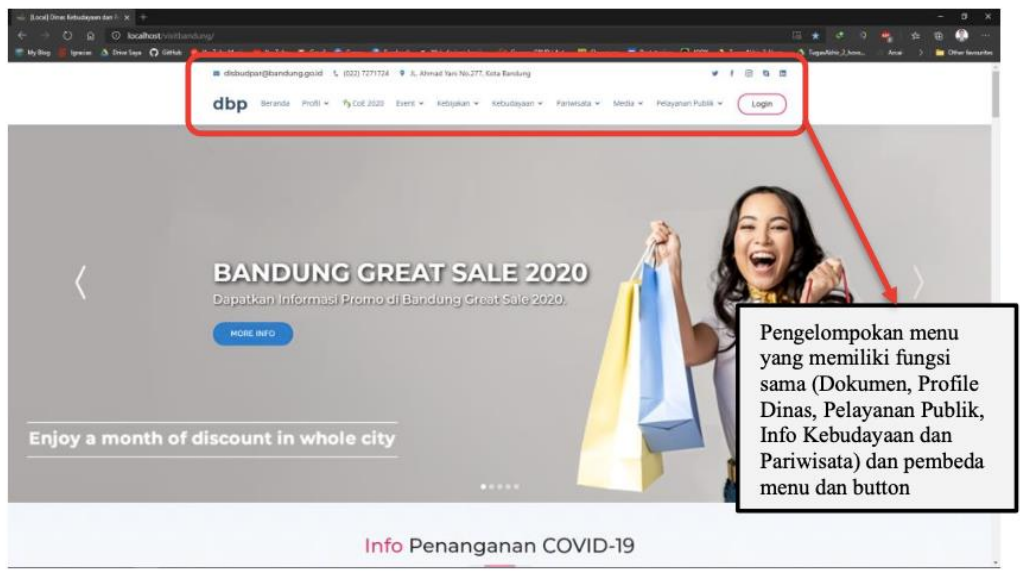

Gambar 5 Tampilan awal website perbaikan

Gambar 5 merupakan hasil desain perbaikan website. Menu yang ditampilkan telah dikelompokkan berdasarkan kegunaan dan tujuannya sehingga dapat memudahkan pengguna dalam melakukan pencarian informasi. Selain itu, untuk mengurangi aksi yang dilakukan pengguna, maka dilakukan perbaikan sesuai panduan 13:6 Minimize User Data Entry sehingga terdapat menu yang ditampilkan pada bagian header menu utama.

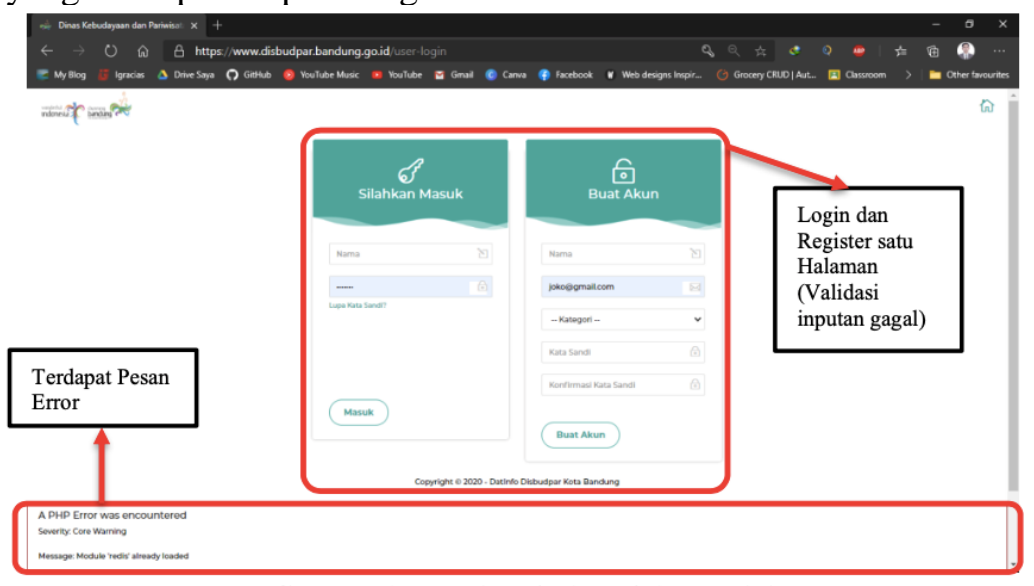

Gambar 6 Tampilan login website saat ini

Gambar 6 merupakan tampilan login website saat ini. Kekurangan pada tampilan ini, yaitu login dan registrasi ditempatkan pada satu halaman yang sama sehingga terjadi kegagalan dalam proses validasi masukan pengguna. Selain itu, tidak terdapat fitur-fitur seperti "ingat password" dan "invisible password", bahkan terdapat eror.

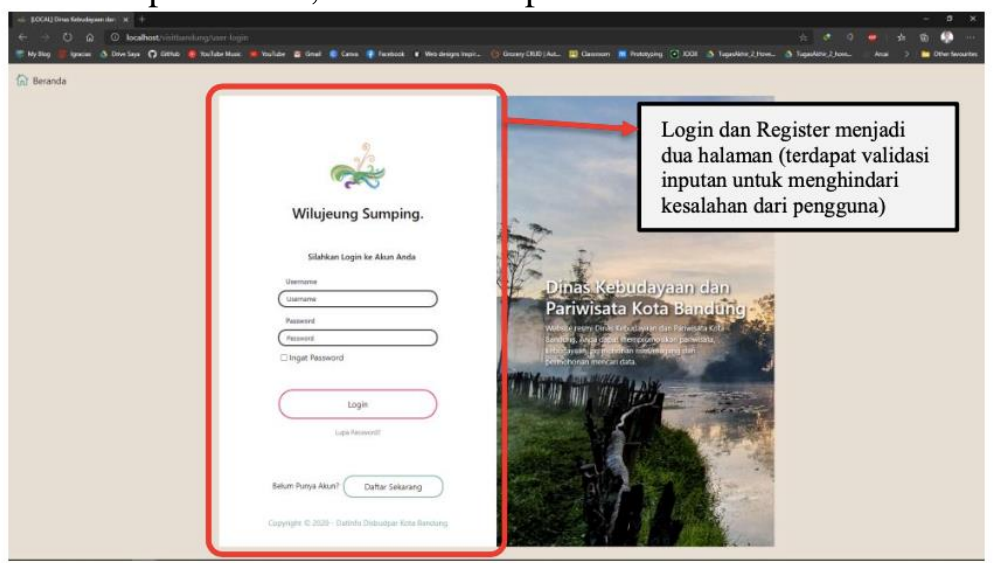

Gambar 7 Tampilan login website perbaikan 
Gambar 7 merupakan tampilan login website perbaikan dimana halaman login dan registrasi akun baru dipisahkan agar proses validasi masukan pengguna tidak gagal. Ditambahkan juga Fitur "Ingat Password" dan "Invisible Password" untuk memudahkan pengguna saat login. Pada halaman registrasi terdapat penambahan pop-up informasi atas masukan pengguna untuk mengurangi kesalahan dalam memasukkan username, password, email dan lainnya sesuai panduan 12:1 Order Elements to Maximize User Performance, 13:11 Anticipate Typical User Errors dan 9:5 Highlight critical data.

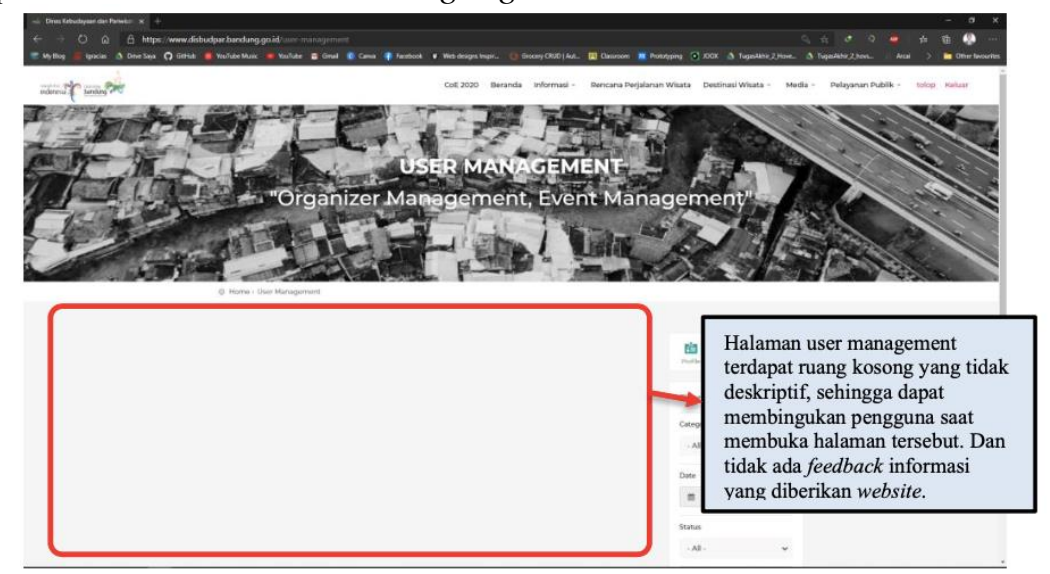

Gambar 8 Tampilan halaman user management website saat ini

Gambar 8 merupakan tampilan halaman user management. Tata letak dan feedback informasi yang diberikan oleh website perlu diperbaiki agar tidak membingungkan pengguna.

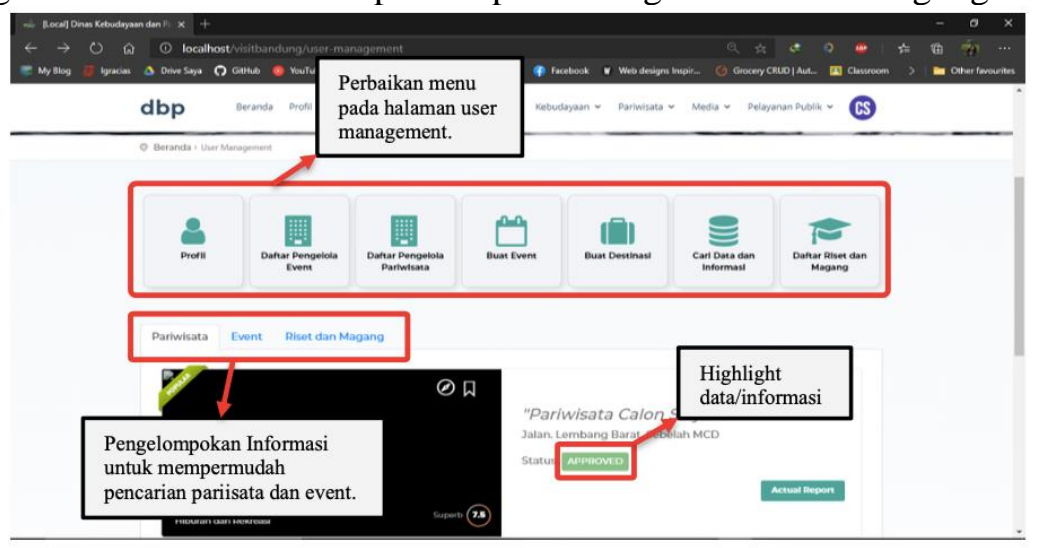

Gambar 9 Tampilan halaman user management website perbaikan

Gambar 9 merupakan perbaikan halaman user management berdasarkan panduan perbaikan 13:1 Distinguish Required and Optional Data Entry Fields, 16:7 Display Only Necessary Information dan 2:10 Provide Feedback when Users Must Wait. Perbaikan yang dilakukan, yaitu menampilkan informasi secara jelas, pengelompokan informasi dan feedback dari website ketika pengguna melakukan sebuah aksi.

\subsection{Evaluasi Website Perbaikan}

Evaluasi website perbaikan dilakukan untuk mengetahui apakah perbaikan usability website yang dilakukan menghasilkan peningkatan level usability website sehingga hasil rancangan perbaikan website dapat digunakan sebagai rekomendasi rancangan website Dinas Kebudayaan dan Pariwisata Kota Bandung. Berdasarkan evaluasi yang dilakukan dengan menyebarkan kembali kuesioner kepada 30 (tiga puluh) orang responden yang sama dengan sebelumnya, website perbaikan mendapatkan nilai rata-rata Importance sebesar 3,90 dan nilai Performance sebesar 4,10. Nilai tersebut menunjukkan bahwa harapan pengguna terhadap 
kinerja dari website telah terpenuhi. Nilai usability point website perbaikan adalah 0,78 sehingga dapat diketahui hasil perbaikan pada 11 (sebelas) atribut permasalahan yang ditemukan sebelumnya berada pada level Usability Good.

\subsection{Hasil Pemetaan Importance-Performance Kuesioner Website Perbaikan.}

Importance-Performance Analysis (IPA) dilakukan terhadap hasil kuesioner perbaikan website untuk melihat penyebaran setiap indikator pertanyaan pada diagram kartesius. Hasil pemetaan setiap indikator pengukuran pada empat kuadran, yaitu Kuadran I: Concentrate Here, Kuadran II: Keep Up the Good Work, Kuadran III: Low Priority dan Kuadran IV: Possible Overkill dapat dilihat pada gambar di bawah ini.

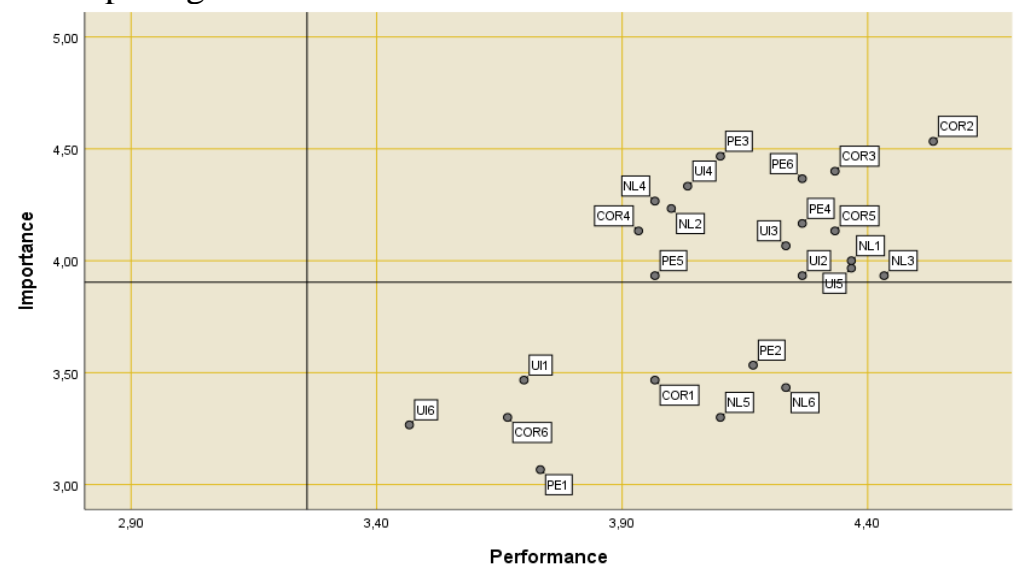

Gambar 10 Pemetaan indikator pengukuran website perbaikan pada diagram IPA

Setelah dilakukan perancangan website perbaikan, 11 (sebelas) atribut pengukuran yang merupakan prioritas perbaikan (COR2, COR3, COR4, COR5, NL1, NL3, NL4, UI2, UI4, PE4 dan PE6) mengalami peningkatan sehingga masuk ke kuadran II: Keep Up the Good Work.

\subsection{Perbandingan hasil evaluasi Usability Website saat ini dan Website perbaikan}

Dalam hasil analisis Importance-Performance website saat ini dan website perbaikan, nilai rata- rata keseluruhan indikator pertanyaan Importance adalah 3,90, sedangkan hasil akhir dari nilai rata-rata Performance website saat ini adalah 3,25 dan website perbaikan adalah 4,10.

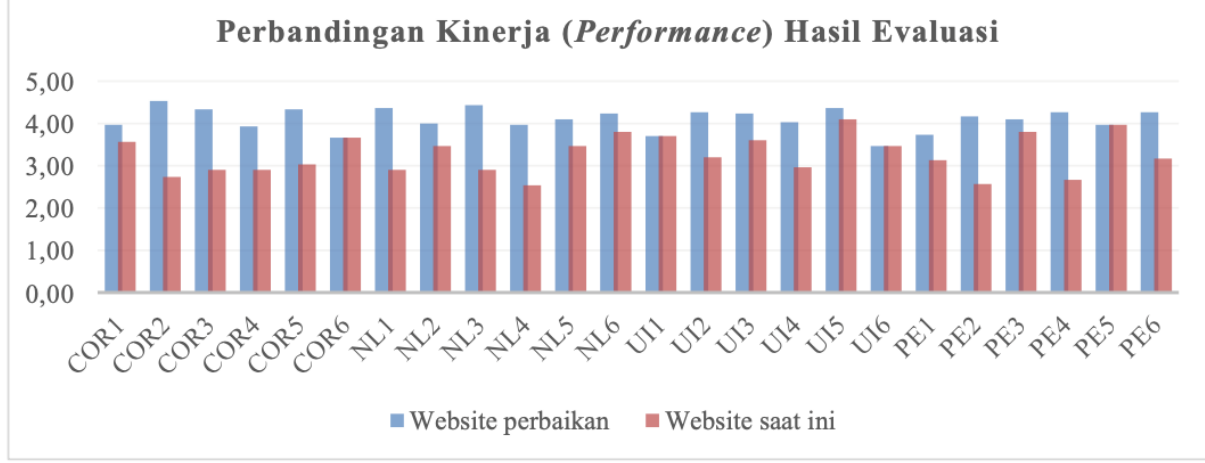

Gambar 11 Diagram perbandingan performance website saat ini dan website perbaikan

Gambar 11 menunjukkan hasil evaluasi website perbaikan lebih tinggi dibandingkan hasil evaluasi desain website saat ini.

\subsection{Analisis Tingkat Kesenjangan (gap)}

Berdasarkan hasil analisis kesenjangan (gap), nilai akhir rata-rata pada website saat ini adalah -0,65 dan pada website perbaikan adalah 0,20. Dapat disimpulkan bahwa keseluruhan perbaikan yang dilakukan telah memenuhi harapan pengguna. Namun, terdapat beberapa atribut 
pengukuran yang nilai kesenjangannya < 0 yaitu COR3, COR4, NL2, NL4, UI4, PE3 dan PE6 dapat dilihat pada gambar 13 dibawah. Hal ini disebabkan nilai rata-rata Performance lebih kecil dari nilai Importance pengguna.

Perbandingan Kesenjangan ( $G A P)$

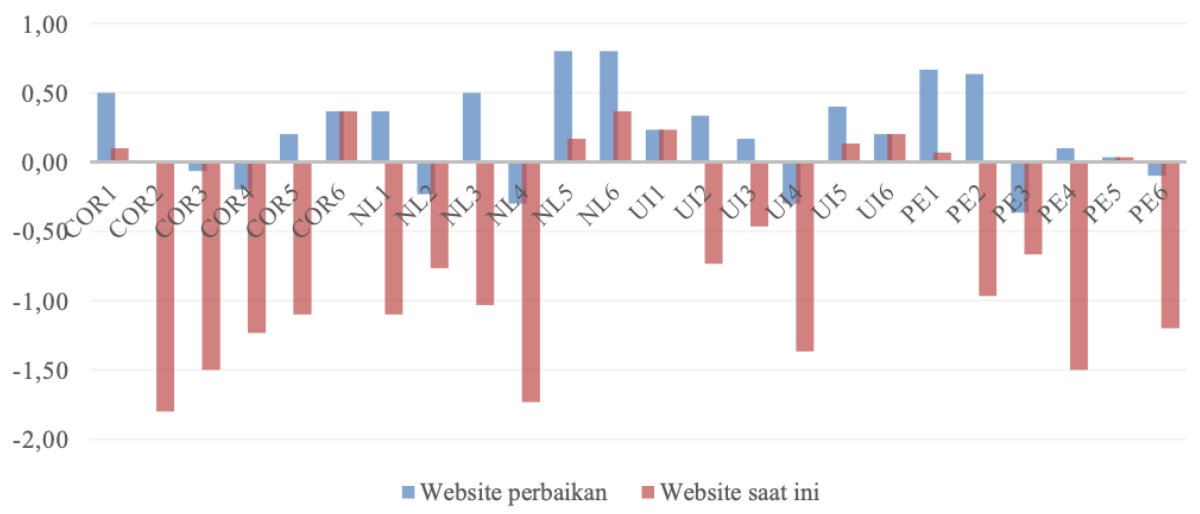

Gambar 12 Diagram perbandingan gap website saat ini dan website perbaikan Tabel 5.

Tabel 4 Tabel perbandingan gap website saat ini dan website perbaikan

\begin{tabular}{|l|l|l|l|}
\hline Rata-rata keseluruhan & Rata-rata Importance & Rata-rata Performance & gap \\
\hline Website Saat Ini & 3,90 & 3,26 & $-0,65$ \\
\hline Website Perbaikan & 3,90 & 4,10 & 0,20 \\
\hline
\end{tabular}

Berdasarkan hasil perbandingan gap website saat ini dan website perbaikan, kepuasan pengguna dalam menggunakan website mengalami peningkatan.

\section{KESIMPULAN DAN SARAN}

Berdasarkan hasil evaluasi dan perbaikan yang dilakukan pada website Dinas Kebudayaan dan Pariwisata Kota Bandung, maka dapat disimpulkan bahwa Usability website saat ini berada pada level Moderate dengan nilai usability sebesar 0,56. Hal ini menunjukkan pengguna belum puas dengan penggunaan website sehingga perlu dilakukan peningkatan usability pada website. Hasil perbaikan website yang dilakukan telah meningkatkan level usability website menjadi level Good dengan nilai usability sebesar 0,78.

Hasil analisis permasalahan dengan menggunakan diagram IPA menunjukkan bahwa terdapat 11 (sebelas) indikator permasalahan yang masuk kedalam kuadran I (concentrate here) sehingga indikator tersebut diprioritaskan untuk diperbaiki. Indikator tersebut adalah COR2, COR3, COR4, COR5, NL1, NL3, NL4, UI2, UI4, PE4 dan PE6. Nilai rata-rata kinerja (Performance) website mengalami peningkatan sebesar 0,84 . Dengan nilai rata-rata Performance website sebelum perbaikan sebesar 3,25 dan rata-rata Performance website perbaikan sebesar 4,10. Hasil evaluasi menunjukkan tingkat kesenjangan website saat ini sebesar -0,65 dan website hasil perbaikan sebesar 0,20. Hal ini menunjukkan bahwa pengguna belum puas terhadap kinerja (performance) website saat ini dan pengguna puas terhadap kinerja website hasil perbaikan.

Untuk penelitian selanjutnya dengan topik yang sama, penulis menyarankan untuk mengambil sampel dari semua kemungkinan pengguna, bukan hanya masyarakat umum saja agar dapat memaksimalkan evaluasi yang dilakukan. Selain itu, peneliti menyarankan menggunakan buku panduan lainnya seperti Usability Guidelines for Accessible Web Design agar perbaikan usability sebuah website dapat lebih baik. 


\section{DAFTAR PUSTAKA}

[1] M. Y. Alfiqie, I. Aknuranda, and N. H. Wardani, 'Evaluasi UsabilityPada Aplikasi UBER Menggunakan Pengujian Usability', J. Pengemb. Teknol. Inf. Dan Ilmu Komput., vol. 2, no. 9, pp. 2599-2606, Sep. 2018, Accessed: Feb. 08, 2021. [Online]. Available: http://jptiik.ub.ac.id/index.php/j-ptiik/article/view/2367/876

[2] A. R. Kadafi, 'Evaluasi Usability Website Sekolah Islam Terpadu Nurul Fikri Depok Menggunakan Web Usability', presented at the Konferensi Nasional Ilmu Pengetahuan dan Teknologi, Bekasi, Agustus 2016.

[3] L. Nasution, I. Aknuranda, and A. Rachmadi, 'Evaluasi Situs Web Pemerintah Menggunakan Metode Webqual Dan Importance-Performance Analysis (IPA) (Studi Kasus: Situs Kecamatan Lowokwaru-Malang)', J. Pengemb. Teknol. Inf. Dan Ilmu Komput., vol. 2, no. 11, pp. 4377-4384, Feb. 2018, Accessed: Feb. 08, 2021. [Online]. Available: http://j-ptiik.ub.ac.id/index.php/j-ptiik/article/view/2911

[4] W. S. Fatmala, S. Suprapto, and A. Rachmadi, 'Analisis Kualitas Layanan Website ECommerce Berrybenka Terhadap Kepuasan Pengunjung Menggunakan Metode WebQual 4.0 dan Importance Performance Analysis (IPA)', J. Pengemb. Teknol. Inf. Dan Ilmu Komput., vol. 2, no. 1, pp. 175-183, Agustus 2017, Accessed: Feb. 09, 2021. [Online]. Available: http://j-ptiik.ub.ac.id/index.php/j-ptiik/article/view/753

[5] E. E. Barus, 'Analisis Kualitas Website Tribunnews.com Menggunakan Metode Webqual dan Importance Performance Analysis', J. Pengemb. Teknol. Inf. Dan Ilmu Komput., vol. 2, no. 4, p. 9, 2018.

[6] N. Oktaviani, 'Analisa Website Media Elektronik Di Sumsel Melalui Penerapan Usability Pada Evaluasi Metode Webuse', in Semina, UN PGRI Kediri, 2017, p. 8.

[7] N. Aini, 'EVALUASI WEBSITE PEMERINTAH KOTA PRABUMULIH MELALUI PENDEKATAN WEBSITE USABILITY EVALUATION (WEBUSE)', J. Ilm. Betrik Basemah Teknol. Inf. Dan Komput., vol. 10, no. 1, p. 6, 2019, Accessed: Feb. 08, 2021. [Online]. Available: https://media.neliti.com/media/publications/290423-evaluasi-websitepemerintah-kota-prabumu-b126a57a.pdf

[8] Q. Aynayya, M. C. Saputra, and D. Pramono, 'Evaluasi Usability Dan Rekomendasi Perbaikan Tampilan Website Seleksi Mahasiswa (SELMA) Universitas Brawijaya', $J$. Pengemb. Teknol. Inf. Dan Ilmu Komput., vol. 2, no. 4, pp. 1446-1456, Agustus 2017, Accessed: Feb. 08, 2021. [Online]. Available: http://j-ptiik.ub.ac.id/index.php/jptiik/article/view/1288

[9] I. K. Dewi, Y. T. Mursityo, and R. R. M. Putri, 'Analisis Usability Aplikasi Mobile Pemesanan Layanan Taksi Perdana Menggunakan Metode Webuse dan Heuristic Evaluation', J. Pengemb. Teknol. Inf. Dan Ilmu Komput., vol. 2, no. 8, pp. 2909-2918, Sep. 2017, Accessed: Feb. 08, 2021. [Online]. Available: http://j-ptiik.ub.ac.id/index.php/jptiik/article/view/1770

[10]J. A. Martilla and J. C. James, 'Importance-Performance Analysis', J. Mark., vol. 41, no. 1, pp. 77-79, 1977, doi: https://doi.org/10.2307/1250495.

[11]M. O. Leavitt and B. Shneiderman, Research-based web design and usability guidelines. Washington DC: Department of Health and Human Services (HHS) and U.S. General Services Administration (GSA), 2006. Accessed: Feb. 08, 2021. [Online]. Available: https://www.usability.gov/sites/default/files/documents/guidelines_book.pdf

[12]Thiam Kian Chiew and Siti Salwah Salim, 'Webuse: Website Usability Evaluation Tool', Malays. J. Comput. Sci., vol. 16, no. 1, pp. 47-57, 2003.

[13]Laura A. Warner, Anil Kumar Chaudhary, and Alexa J. Lamm, 'Using ImportancePerformance Analysis to Guide Extension Needs Assessment', J. Ext., vol. 54, no. 6, 2016. 